\title{
論蘇聯水交氣象工作 對國民經濟的專業服務
}

K. A. 斯考布采夫

社會主義國民經率的猛烈的高浱和改造自然 的任務，以嶄新的姿態提出了水文氣像服務的問 題, 我國一切國民經游部門對於這一問題都非常 關心。

巨大的水利建築物的創建, 新的城市、鐵路 及公路的建設, 現在都要求水文氣像部門供應有 關各種情况的資料, 並且要求水文氣像部門就各 地區、航路、幹綫或設計中的建築工程從事水文 氣象學方面的研究。

薊聯的水文氣無工作機構，有着一系列的科 學研究所、地球物理觀象台、水文氣售預報所, 並在全國篹国內，分栃着數干個水文氣像台站; 它組織了對於工業、農業、文化建設以及祖國國 防的水文氣像服務工作。

在水交氣像第各個國民經濟部門服䋍的工作 中所遭到的嚴重困難, 乃是水交氣像工作人員對 於各個被供隹機關所提出的要求膫解得還不多, 這是因篇各部和各主管機關僅在最近爾年來卡向 水文氣像工作機構提出了自己的具體需要。我們 必須精密地㸴究遭些需要, 因窟唯有正確地瞭解 了被供應機關的要求，才能組織水交氣象對國民 經游的專業化服䂆。

包版航空隊的活動要在多方面随氣像條件而 嫥移, 它是首先向水文氣像工作提出自己具踹要 求的單位之一。它要求我們以必要的氣缘資料來 保障航空工作, 以健使鴐駛員能够選擇最有利的 (能够促進安全起飛並按期飛行的) 氣象條件從 吏飛行。

篇了以氣像工作來保障民用航綫上的狤行安 全, 在各個航空站上設立了航空氣象台網。選些 氣象台的任務就是保證以航綫天氣預報、風暴警

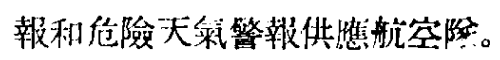

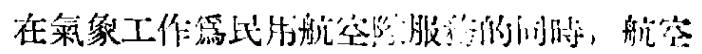

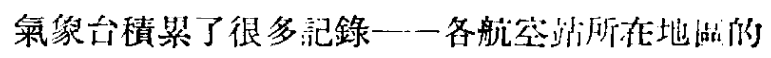

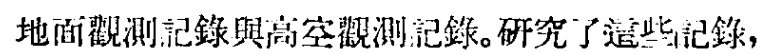
就可以用圖表來閶明特殊的、地方性的天乘情况。 飛行旨也都大大地加品了策象力面的訓練, 因而

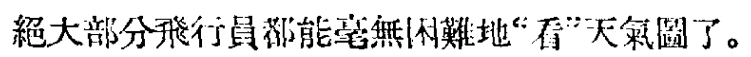

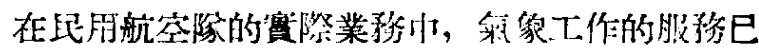
成篇一個不可缺少的組成部分。

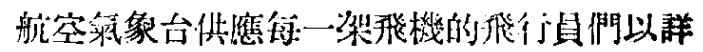
細的航䋐天氣預報。在這種預報中, 除了载明着

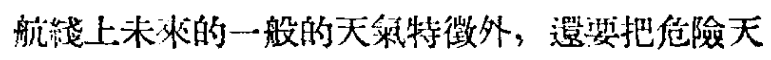
氣現象特品標明出來。等如, 在預報飛機程冰時, 一定要指明飛機在航綫上的那一地段及那一古度

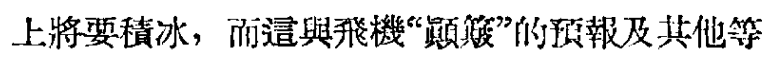

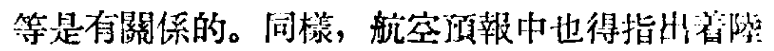
點在飛機着陸時的詳湅的天氣特徵。

有了正確的、有系統的氛象聚業化服扮的工。

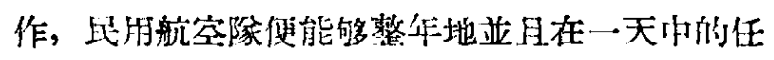
何時間安全颛定期地飛行了。

但是旦用航空榢並不滿足於現在濖種僅有短 期（幾小時）天氣預報的服務工作。篇了正確地 計剖飛行工作, 特別是在利用飛機來播種、䍀治 害螼、篇農作物施肥或從事其他工作的時候, 他 們必須知道較長時間的未來天氣情况, 因而對長 期預報有了巨大的要求。

民用航空隊對氣像服務工作的要求濖不止於 此。當民用航空榢要設計一焂新航綫㭙, 它就要 廣泛地使用水交氣像機棈現有的水交氣象資料, 這些資料是多年觀测所得來的。长航部鬥釗丵着 航空的需要及特點適當地使用了通些資料, 就能 


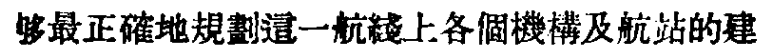
立。

氣象工作保障是航飛行的各種成就，都是水 文氣象部門與比航榢各部門的技術人員相互瑟 助、相互配合所得到的結果。

在氣累情况異常複雜的一整天或全年的過程 內, 在不同高度上所進行的長程飛行, 對水文氣 象業移部門提出了更高的要求。篇了滿足這些要 求, 水文氣像業務部門必須全面地提高觀测工作 的質量, 以健使長期天氣預報的準確性獲得顯菩 的提高, 並使關於航空的危險天氣警報能够具有 慗大的預見性。

以往水文氣缘工作第海上及內河船榢、漁業、 動力工業及森林工業服務的實践, 說明了這些國 比經沙部門是非常需要水文氣像專業化服務的。

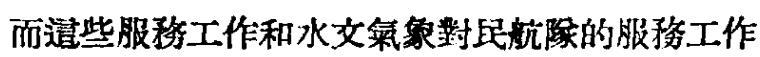
當然有所不同。

最近偻年來, 預報工作者與預報使用者在工 作的配合方面已取得了一些經駿。這侹使我們有 可能給水文篓像工作規定許多篇國政沾各部門 進行專業化服務的方式。但是這並不等於喰已經 完全解决了如何以水文氣家工作來保障國灵經濟 各個部門的問題。對於一個工程技術方面的氣缘 人員來馀, 工作不是要求他以預垠和專業化水文 氣像资料作简單的技術性的服務, 而足是要求他主

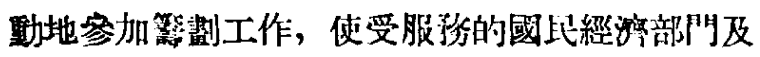
文化建設部門能够最有效地使用造些頂報和其他 資料。

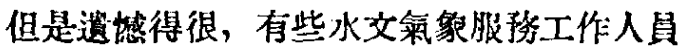
至今還不清楚各種專業化服務的內容。當蘇聯部 長會議水文気像總局開會討論“對於農業的覀業 化服務的紃驗"”一報告時, 這一問題表現得非常明 影。由於造一次討論, 委員會健揭發了在組織和

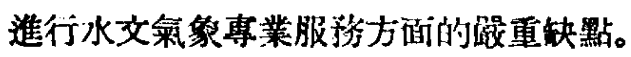

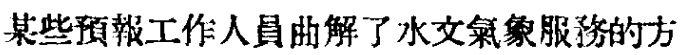
式, 於是水文氣售總局局長A.A.卓勞圖辛健不得

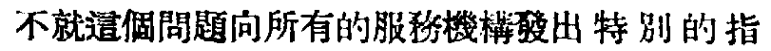
示。

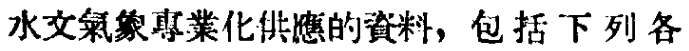
項:

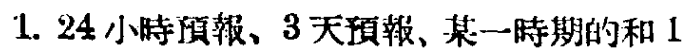
月的預報，運是用來服移的基本資料。在以上各
程預報中，除了 1 月預報以外，都應當在預告未 來的水交氣像要素時照顧到受服务的國比經济部 門的要求。對於那些有害於各受服䅂國纪經源部 門的水文策象的現象, 預報應力求㟆確，並打破 以往的準確性紀錄。

2. 關於蛽際水交氣象現像的專業化情報。

3. 指導性的和部述性的水文氣像資料、専門 的計算、有代表性的水文氣象資料和其他資料。 在紜製這些資料時應當照顧到受服務部門的具體 要求。

4. 針對各國民經游部門的需要而進行的一些 必要的研究工作的報告。

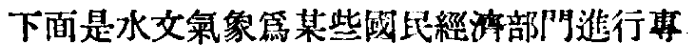
業化服移的幾個例子:

有一度, 一連幾年南庫㥳息各㴧業機構沒有 完成春季㴡期的計劃。經過分析, 墢現計劃沒能 完成的原因之一是水文氣像方面的地病。

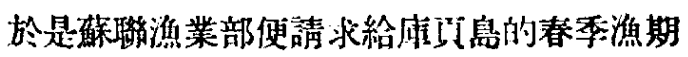
以水文氣象方面的保障, 根據這一請求, 便在那

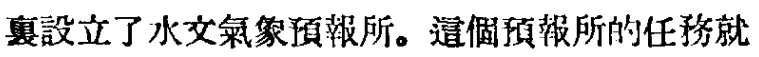
是以最大的努力来協助各漁業機榡, 及時地發有 有關開始捕魚以前和捕魚期中各程菊象保件的完 備的情颠, 並以此保證捕魚計劃的完成。

有一次, 各漁業機棈推测在日本海的某一地

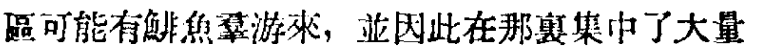
的捕魚工具。但是根據預報赛查了这一推测並徵 求了領報員的意見以後, 臬新义確定了在日本海

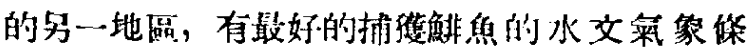

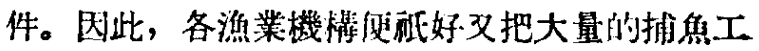
具從日本游上前一地區移到後一地區來。

事斯上，遭一春季㴧期中，後一地區來了極

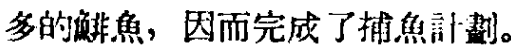

如果潐業機蓝僅僅在形式上接受水交氣像預 報和情㧐，而在自己的工作中並不佔計到水文策 象因素的話, 那麼計劃优不會完成, 國家也就無 法多得大量的焦。

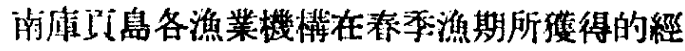

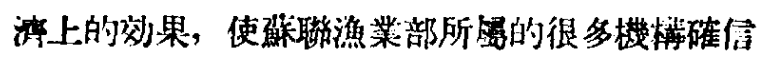

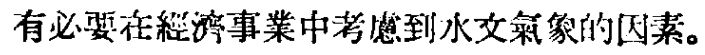

鄂篗次克海的漁業機構, 經與遊東水文氣缘 局其润研究了專業化服㢷的方式, 登在自己的工 作中開始考虑水交氣像集作以後，現在已初步得 
到了良好的成效。

在內河航運工作方面，水交工作上的保障有 着極大的意義。水文預報工作者必須監視着汇水 的“生活狀態”，與自己的需求者保持着緊密的聯 慗，並把一切有關河流情况變化的（不管是預見 到的或是已經開始了的）情報供給他們。有了組 織得很好的水文服務工作，就可以防止因水文氣 象因素而应生的船隻破椇等事件。

新西伯利严水文氣象局在水文工作方面箩西 伯利亞西部內河航運局服務的經驗, 可以作需專 業化服㑧的一個實例。

水文氣像預報所起初用水交方面的詻詢報告 服移於內河航運局, 報告的內容是 10 天以內沿河 許多地點叮保登的最低水位。根據選些報告, 航 運局便有可能調整船舶的裝载量。篇了調整裝裁 量, 內河航運局必須在西伯利亞一條河的河口上 設立一個測量站，來测量船隻的裝載量是否適 當。

由於設立了測量站，由於㯰測量站在自己的 工作中應用了水文的嫆詢報告, 所以在 1950 年西 伯利亞諸河水淺的時候，航運局能够用減輕船舶 載重的方法來防正因船舶裝載過重所産生的擱淺 現唏。

下酥是另外幾個䟱業化服務的例子。

某次關於土拉河和塔伯爾河薄冰出現及河水 凍結的頙報汥有報蕉。凍結過程 來早了11-23 天，而且是很多年來最早的一次。

這幾條河上各船隊的船隻都出乎意料地陷入 冰中。當時的急迫問題就是是否要卸䡋。預報工 作人員（分析預報人員及水文工作人員）仔細地 分析了他們所有的一切資料，得出了一個結論， 就是: 水文氣象環境即將改變, 已臨之嚴寒即將 篇一長時期的融雪天氣所代替。於是水文氣像部 門侹勸告航運局從這一結論出㡎，探取適當的解 决辦法。結果, 船隻便沒有卸㦲。隨着融雪天氣 的來臨, 塔伯爾河及土拉河便解凍了, 而船隻繼 續前進，順利地到達了江口。

現代技衡還不能保證預報完全蕉確。但是如 果因䉆預報沒能報潐，受服務部門就要遭受很大 的困難甚至其某一部分可能因之受到損失的話, 逗時預報人員又能起些什麼作用呢?

1949 年末至 1950 年初裹海上冷得與徍常 不
同。從 1 月初到 2 月中旬, 凍粘過程瑶展得非常 块，而在 1 月底時，整個北部海洦即已爱完全凍

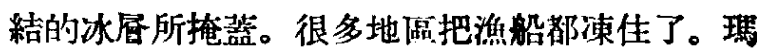
品赤卡琳港及其附近地區都第大塊的冰所封鎮, 而琵重地防碍了船隻航行。冰塊的漂流給海地建 築物帶來了許多威禾。

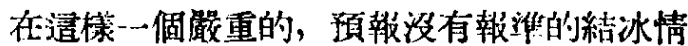
次中，在它對海上建築物的現實的威辟下，便必 須進行特别的水交氣像服移工作。篇此成立了水 交特別組。狺個組的組成人員包括與㐮游上通一 複雜而又哏難的情况有關係的各部局的代表們， 它的任務就是作第一倜進行特殊的水交氣像服務 的指揮部。

逻個組用天氣预報、冰凍预称和有關水文氣 象條件的筫際情况的情報進行了服预工作。他們 除了考虑沿海各台站的雚测資料外，還組織了冰 的特別偵察（用飛機或船），並把偵察所得的資料 楥泛地應用起來。

指揮部不斷地報告水文氣隽狀况，正確地並 有組織地收集情報，預報工作人員也都皘極地參 加了指揮部的工作，造一切大大地有助於防止事 故的發生, 特别是有助於防止海上建築物的損壞.

因此，即使在預報沼有報淮而受服務的國民 經橓部門遭受到祳重困難的時候，水文氣象部門

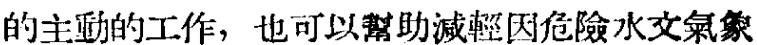
因素的破壞作用所招致的不造後果。

大家知道，森林工業是重要的國战經游部鬥 之一，而木筏浮運木材又是森林工業的一個組成 部分。例如在奥涅日斯克湖，80\%的木材是用水 筏隶運輸的。卡糸利阿一芬闌蕉維埃注會主義基 和國水文氣售局最重要的任務就是篇水筏運輸進 行水交氣像服教。

挠年以前，汇船航行方面賟沒有水文氣象的 服㐨，那時只能“盲目”地拖着木笺承浮運木材， 因而使木質遭受到战重的損壞。後來，篇了保障 木材浮運工作，僅僅應用了一般的天氣預報，便 使木材的損壞量減少到原損壞量的四分之一。水 文象象工作者及航運工作者在水交氣象服務方的 的經驗隹年都增加着，亚且找到了這種服杼的最 合理的方式。由此便出現了所詡“水文乘象”航 綫——根據水交莱像部門的蜼告而規定的航綫， 根據赛際資料和預期中的水文氣像佟件，沿着這 
炛航路浮運朴朴是最安全的。經過精密研究, 言丁 定了用水文氣象工作保障浮運木材的辦法, 它的

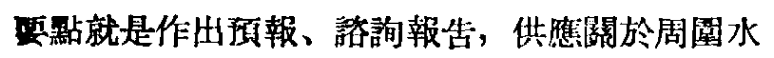

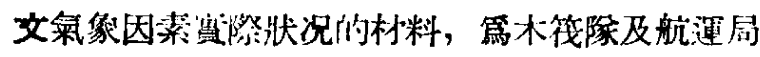
服䇨。

水交楊象工作對木材浮連的服䅂如果能組織 得很好，在服務中文能考急到木筏榢的特殊需 要, 再加上船長們也都能正確地應用有關危險天 氣條件的預報及風暴警報, 那末就能保證木箋隊 䯩顧地完成計劃, 並在很多場合中防正木材遭受 損墒。
以上列舉的專業化服務的望例喰明了, 如果

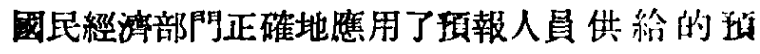
報、警報以及水文氣象方面的其他勸告，那末国 之而得的經流上的效果將是極第 $\mathrm{E}$ 大的。從以上 敌例中也可得出另一個結部, 那便是水交氣象機 棈應當在最短的時間內，從一般方式的水文氣象 服務轉入專業化方式的服颖。

水文氣像部門的一切成員, 首先是猊報工作 人員, 都應営程極地寥加這一工作, 以完成第國 比經游部門服䅂逗一首要任䅂。

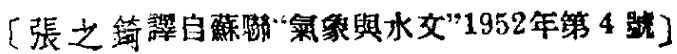

\section{更正}

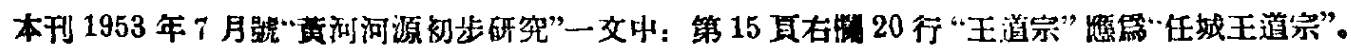

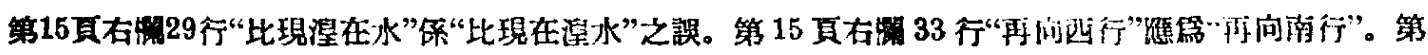

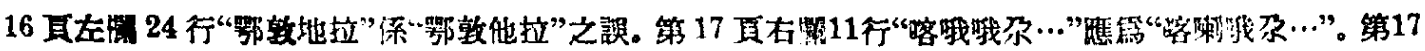

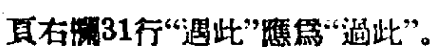

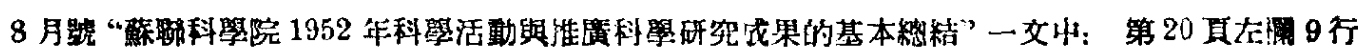

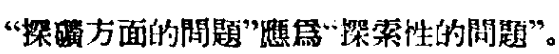

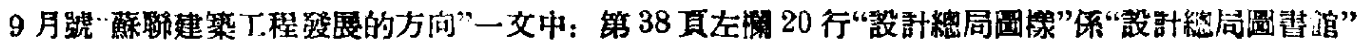

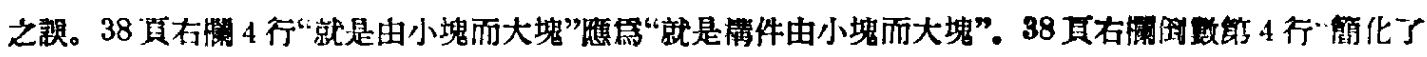

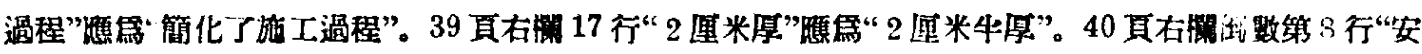

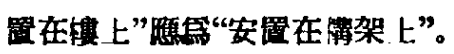

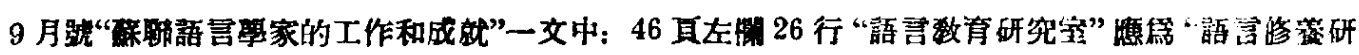

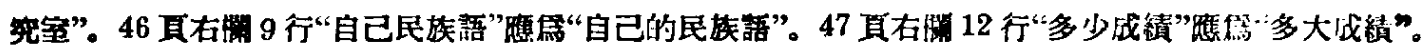

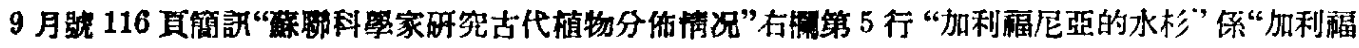
尼亚的杠杉”之䜋。 